\title{
Evaluation of maternal and fetal outcomes in pregnancy with heart disease
}

\author{
Jayshree Mulik, Rahul Patil*
}

Department of Obstetrics and Gynecology, Government Medical College and Hospital, Nagpur, Maharashtra, India

Received: 30 September 2018

Accepted: 22 October 2018

\section{*Correspondence:}

Dr. Rahul Patil,

E-mail: rahulpatilobgy@ rediffmail.com

Copyright: (C) the author(s), publisher and licensee Medip Academy. This is an open-access article distributed under the terms of the Creative Commons Attribution Non-Commercial License, which permits unrestricted non-commercial use, distribution, and reproduction in any medium, provided the original work is properly cited.

\begin{abstract}
Background: Heart diseases complicate $>1 \%$ of all pregnancies and is the leading indirect cause of maternal deaths. Present study attempted determining the maternal and fetal outcome in pregnant women with heart disease using various relevant parameters.

Methods: A total of 44 consecutive cases of heart disease with pregnancy that were admitted at the study centre from December 2013 to August 2015 were included and analyzed for outcome with respect to age, parity, associated comorbidities, nature of cardiac lesions, type of valvular involvement, NYHA functional class, type of anaesthesia used, mode of delivery, maternal outcome, fetal outcome, birth weight of babies and maternal and fetal mortality, if any.

Results: Rheumatic heart disease $26(59.1 \%)$ was the commonest lesion observed to be affecting pregnant patients, followed by congenital heart disease $(10,22.7 \%)$. Mitral valve $(30,68.2 \%)$ was found most commonly affected, followed by aortic valve $(10,22.7 \%)$. Regurgitant lesions $(26,59.09 \%)$ were commoner than stenotic ones (14, $31.81 \%)$. Four $(9.1 \%)$ patients went into left ventricular failure and had to be admitted to ICU. Of these, one patient $(2.3 \%)$ died.

Conclusions: Maternal heart disease is one of the important causes of maternal mortality. The obstetrician needs to have strong suspicion of the entity right from the start, so as to improve upon the maternal as well as fetal outcomes.
\end{abstract}

Keywords: Heart disease, Obstetric outcome, Pregnancy

\section{INTRODUCTION}

Pregnancy and the peripartum period are associated with considerable cardio circulatory changes, which are usually well tolerated by the mother. However, the increased cardiac demands imposed by those changes may at times unmask cardiac disease in presumably normal women or increase mortality and morbidity in women with established heart disease. A recognition and understanding of these significant changes is essential for providing optimal care to obstetrical patients with cardiac disorders. ${ }^{1}$ Heart diseases complicate $>1 \%$ of all pregnancies and is the leading indirect cause of maternal deaths in developed countries. ${ }^{2}$ In an analysis of maternal mortality between 1987 and 2005, the causes previously responsible for most maternal deaths-hemorrhage and hypertensive disorders had progressively decreased rates, whereas deaths attributed to cardiovascular diseases had the greatest percentage increase. ${ }^{3}$ Similarly, the rate of maternal mortality due to cardiac diseases increased from 1.65 to 2.31 per 100000 births between 1997-1999 and 2006-2008. ${ }^{4}$

With the advent of various non-invasive techniques and cardiac catheterisation it has now been possible to precisely evaluate the anatomic defects in the heart and 
hemodynamic condition of the patient. Thus, any intervention if at all required can be undertaken by closely monitoring the mother and fetus during antenatal period, labour and postnatal period. ${ }^{5}$ The obstetrician should be well versed with the probable complications that may affect the outcome; which entails being familiar with physiological, hemodynamic changes occurring during pregnancy, effects of pregnancy on cardiac disease and of cardiac disease on pregnancy and measures for effective care. ${ }^{6}$ Present study attempted determining the maternal and fetal outcome in pregnant women with heart disease using various relevant parameters.

\section{METHODS}

The Study was Hospital based prospective and observational at a tertiary care teaching hospital with the study period from December 2013 to August 2015. The study sample was 44 patients.

\section{Inclusion criteria}

- Only those pregnant ladies with heart disease who were got registered, admitted and delivered during the study period.

All the participants were subjected to routine antenatal investigations, ECG and 2D-Echocardiography; apart from detailed history and clinical examination. Generally, patients were managed on OPD basis by the obstetrician (PI) and cardiologist opinion was ought to whenever indicate. Patients in NYHA class I \& II were admitted at 38 weeks of period of gestation for safe confinement.

All the enrolled cases were analysed for outcome with respect to age, parity, associated comorbidities, nature of cardiac lesions, type of valvular involvement, NYHA functional class, type of anaesthesia used, mode of delivery, maternal outcome, fetal outcome, birth weight of babies and maternal and fetal mortality, if any.

\section{Statistical analysis}

The data was analysed using SPSS (version 20); by applying unpaired t-test and ANOVA wherever applicable. Approval from Institutional Ethics Committee was obtained before start of the study. Informed written consent was obtained from each patient before participation in the study.

\section{RESULTS}

The study is a result of 44 cases of heart disease with pregnancy that were admitted in the participating hospital from December 2013 to August 2015. In all, there were 3890 births giving case incidence rate of $1.13 \%$.

Out of 44 cases, majority $(18,40.9 \%)$ were in the age group 21-25 years age group, $14(31.8 \%)$ between $26-30$ years, $6(13.6 \%)$ were teenage pregnancies, $4(9.1 \%)$ between $31-35$ years and 2 cases $(4.5 \%)$ were $>35$ years in age. Nine cases $(20.5 \%)$ were primigravida with 35 $(79.5 \%)$ being multigravida. Nineteen cases $(43.2 \%)$ were nulliparous, $18(40.9 \%)$ were primiparous and 7 $(15.9 \%)$ were multiparous.

Out of 44 cases, $27(61.4 \%)$ had no prior abortions, 12 cases $(27.3 \%)$ had one abortion and 5 cases $(11.3 \%)$ had more than 1 prior abortion. As for gestation age, six cases (13.6\%) were preterm, $34(77.3 \%)$ were term pregnancies and 4 cases $(9.1 \%)$ were post-dated. Twenty-one cases (47.7\%) had comorbidities, while $23(52.3 \%)$ had no associated comorbidities. Majority of patients (42, 95.5\%) belonged to NYHA class I and 2 (4.5\%) patients belonged to NYHA class II. No participant belonged to NYHA class III and class IV. Analysis of the type of cardiac pathology found in this study showed Rheumatic heart disease to be the most common entity affecting pregnant patients, present in as many as 26 (59.1\%) cases. Congenital heart disease $(10,22.7 \%)$ was second commonest lesion. Eight patients $(18.2 \%)$ had some other lesions (Table 1).

Table 1: Type of cardiac lesion in pregnant women with heart disease.

\begin{tabular}{|l|l|l|}
\hline Heart disease & Number of patients & $\%$ \\
\hline Congenital heart disease & 26 & 59.1 \\
\hline Rheumatic heart disease & 10 & 22.7 \\
\hline Other lesions & 8 & 18.2 \\
\hline Total & 44 & 100.0 \\
\hline
\end{tabular}

Analysis of type of valvular involvement showed mitral valve $(30,68.2 \%)$ to be the most commonly affected, followed by aortic valve $(10,22.7 \%)$, septic lesion $(6$, $13.6 \%)$, with other lesions $(10,22.7 \%)$ making up the numbers.

Table 2: Distribution of cardiac lesions amongst women with heart disease.

\begin{tabular}{|l|l|l|}
\hline \multicolumn{2}{|c|}{$\begin{array}{l}\text { Number of } \\
\text { patients }\end{array}$} & $\%$ \\
\hline Valve involvement & 30 & 68.2 \\
\hline Mitral Valve & 10 & 22.7 \\
\hline Aortic Valve & 06 & 13.6 \\
\hline Tricuspid Valve & 10 & 22.7 \\
\hline Other lesions & & \\
\hline Type of lesion & 26 & 59.09 \\
\hline Regurgitant lesion & 14 & 31.81 \\
\hline Stenotic lesion & 12 & 27.3 \\
\hline Surgically corrected lesion & 08 & 18.18 \\
\hline Regurgitant + Stenotic lesion & 07 & 15.9 \\
\hline Valve prolapse & 06 & 13.6 \\
\hline Pulmonary artery hypertension & 06 & 13.6 \\
\hline Septal defects & &
\end{tabular}

Regurgitant lesions (26, 59.09\%) were the commonest ones, followed by stenotic ones $(14,31.81 \%)$. Combined 
regurgitant and stenotic lesions were noted affecting 8 $(18.18 \%)$ cases. Surgically corrected heart lesions (12, $27.3 \%)$, valve prolapse $(7,15.9 \%)$ and pulmonary artery hypertension $(6,13.6 \%)$ were the other lesions (Table 2$)$.

Out of total 44 participants, $22(50 \%)$ had normal vaginal delivery, while $5(11.4 \%)$ patients had instrumental delivery mainly to cut down the 2nd stage of labour. Seventeen patients $(38.63 \%)$ underwent Caesarean section, out of which 9 (20.5\% of total) procedures were elective for various obstetric indications, and $8(18.2 \%)$ had to undergo emergency procedure for fetal causes.

Analysis of type of labour revealed that 30 (68.2\%) patients came in spontaneous labour; of which 21 had normal vaginal delivery, 4 had instrumental delivery and 4 underwent caesarean section. Only 3 patients were induced for obstetric causes, of which 1 had normal vaginal delivery, 1 had instrumental delivery and 1 underwent caesarean section (Table 3).

Fetal outcome analysis revealed that out of 44 neonates born to pregnant patients with heart disease, $33(75 \%)$ had normal birth weight $(>2.5 \mathrm{~kg})$ while $11(25 \%)$ were born with low birth weight $(<2.5 \mathrm{~kg})$.

Six (13.6\%) were born preterm, $2(4.5 \%)$ had intra uterine growth retardation and $2(4.5 \%)$ neonates had to be admitted to NICU. However, there were no intrauterine fetal demise as well no neonatal mortality reported in the study.

Four of $44(9.1 \%)$ pregnant ladies with heart disease went into left ventricular failure and had to be admitted to ICU. Of these, one patient (2.3\%) died.

Table 3: Distribution of cardiac lesions amongst women with heart disease.

\begin{tabular}{|c|c|c|}
\hline & Number (44) & $\%(100 \%)$ \\
\hline \multicolumn{3}{|l|}{ Mode of delivery } \\
\hline Vaginal & 27 & 61.4 \\
\hline Normal delivery & 22 & 50.0 \\
\hline Instrumental delivery & 5 & 11.4 \\
\hline Caesarean Section (LSCS) & 17 & 38.6 \\
\hline Elective LSCS & 9 & 20.5 \\
\hline Emergency LSCS & 8 & 18.2 \\
\hline \multicolumn{3}{|l|}{ Type of labour } \\
\hline Spontaneous & 30 & 68.2 \\
\hline Induced & 3 & 6.8 \\
\hline Caesarean Section & 11 & 25.0 \\
\hline
\end{tabular}

\section{DISCUSSION}

With this study, maternal and fetal outcomes in 44 pregnant women with heart disease were assessed using various relevant parameters. Majority of the patients were in 21-25 years $(40.9 \%)$ and $26-30$ years $(31.8 \%)$ age groups and were multigravida $(79.5 \%)$. The definitive relationship between age and parity couldn't be established in the study. Nevertheless, Age and parity have been reported to be of lesser significance in the literature, then other variables. Maternal heart disease is one of the most important causes of maternal mortality. We observed the incidence of cardiac disease to be $1.13 \%$, which is close to $0.98 \%$ observed by Asghar et al and $1.3 \%$ observed by Vidyadhar et al as well as a study at PGIMER, Chandigarh. ${ }^{7-9}$ Rheumatic heart disease is the commonest cause in developing countries; while congenital heart disease predominates amongst causes in the developed world due to improved survival of children with congenital heart diseases. Analysis of the type of cardiac pathology in the present study showed Rheumatic heart disease to be the most common entity, present in $59.1 \%$ cases, followed by congenital heart disease at $22.7 \%$. These results were comparable to previous similar study by Pratibha et al and Vidyadhar et al reporting the incidence at $62.6 \%$ and $77.0 \%$ respectively. ${ }^{8,10}$ Walkiria et al also reported the incidence of rheumatic heart disease at $55.7 \% .{ }^{11}$ Amongst patients with heart disease in present study, mitral valve was the commonest lesion affected $(68 \%)$. Although almost all the previous similar studies also reported mitral valve to be the commonest one affected, the lesion reported most commonly was mitral stenosis, unlike mitral regurgitation (47.7\%) observed by us. ${ }^{9-11}$

Majority of pregnant patients with heart disease in present study were in class I $(95.5 \%)$ and remaining $4.5 \%$ in class II. Various studies report varying severity of dyspnea. Deshmukh et al found majority (62.7\%) belonging to class I. ${ }^{12}$ However, studies by Sawhney et al and Pratibha et al reported only $22.6 \%$ and $28 \%$ patients respectively to be belonging to class $\mathrm{I}$, with majority belonging to class III and class IV. ${ }^{10,13}$ Favorable NYHA functional class observed in present study could be explained by the fact that all the patients were booked during early gestation, along with regular antenatal check-ups and aggressive management of conditions which could precipitate cardiac complications like anemia and respiratory infections. Another confounding factor is that 12 patients had undergone cardiac surgery, which improves NYHA grading significantly. More cardiac complications were reported in the non-operated group, which is similar to that reported by various other studies. ${ }^{8,10}$ There were no cases of endocarditis, pulmonary embolism or arrhythmias; which could be explained by early detection and aggressive treatment of infections with antibiotics during antenatal period, early hospitalization and use of prophylactic anticoagulation in high risk patients.

The rate of normal delivery to cesarean section reported in the present study (50:39) is comparable to the results of studies by Pratibha et al (73.5:23.5) and Vidyadhar et al $(62: 17){ }^{8,10}$ The difference between studies could be explained by varying obstetric indications which required caesarean section or instrumental deliveries. As far the potential complications, the rate of premature babies, 
intrauterine growth retardation and still birth were found not increased in pregnant patients as compared to general population of pregnant women. Walkiria et al and Pratibha et al10 reported similar incidence of preterm neonates (13\% and $12 \%$ respectively). ${ }^{11}$ Analysis of birth weight of neonates in present study showed the incidence of low birth weight to be around $25 \%$. The observations from previous researchers varies greatly; with Sawhney et al reporting it at $18.2 \%$ and Pratibha et al at $37.4 \% .^{10,13}$ One outlier was the study by Vidyadhar et al8, wherein significantly higher incidence $(60 \%)$ of low birth neonates was reported. We observed maternal death in only one patient $(2.3 \%){ }^{8}$ This patient underwent emergency caesarean delivery for cord presentation. Similar results were noted in available literature. ${ }^{10,11}$

Funding: No funding sources

Conflict of interest: None declared

Ethical approval: The study was approved by the Institutional Ethics Committee

\section{REFERENCES}

1. Trinidad D, Cox RA. Heart diseases during pregnancy. P R Health Sci J. 2006:25(3):259-65.

2. Simpson LL. Maternal cardiac disease: update for the clinician. Obstet Gynecol. 2012;119(2 Pt 1):345-59.

3. Berg CJ, Callaghan WM, Syverson C, Henderson Z. Pregnancy-Related Mortality in the United States, 1998 to 2005. Obstet Gynecol. 2010;116(6):1302-09.

4. Cunningham FG, Leveno KJ, Bloom SL, Spong CY, Dashe JS, Hoffman BL et al. William Obstetrics ,24th Edition, Aplleton and Lange 2014;973.

5. Bitsch M, Johansen C, Wennvold A, Osler M. Maternal heart disease, a survey of a decade in a
Danish University Hospital. Acta Obstet Gynecol Scand. 1989;68(2):119-24.

6. Fernando Arias. Practical guide to high risk pregnancy and delivery, $2^{\text {nd }}$ ed;P:48-52.

7. Asghar F, Kokab H. Evaluation and outcome of pregnancies complicated by heart disease. J Pak Med Assoc. 2005;55(10):1-2.

8. Vidyadhar B, Singh R, Shinde K. Clinical study of heart disease complicating pregnancy. IOSR J Pharm 2012;2(4):25-28.

9. Guleria R, Vashist K, Dhall G, Grover A, Wahi P. Pregnancy with heart disease: Experience at PGIMER, Chandigarh. J Physicians India 1990;38(12):902-6.

10. Pratibha D, Kiranmai D, Rani VU, Vani NG. Pregnancy outcome in chronic rheumatic heart disease. J Obstet Gynecol India. 2009;59(1):41-46.

11. Walkiria S, Eduardo G, Jose Antonio F, Maxgrinberg, Maria R, Marcelo Z et al. Pregnancy in patients with heart disease: Experience with 1000 cases. Clin Cardiology 2003;26(3):135-42.

12. Deshmukh MA, Desai S, Motashaw ND. Heart disease in pregnancy. J Obstet Gynecol India 1979;29:996-99.

13. Sawhney H, Aggarwal N, Suri V. Maternal and perinatal outcome in rheumatic heart disease. Int $\mathbf{J}$ Gynaecol Obstet. 2003;80(1):9-14.

Cite this article as: Mulik J, Patil R. Evaluation of maternal and fetal outcomes in pregnancy with heart disease. Int J Reprod Contracept Obstet Gynecol 2019;8:151-4. 